\title{
Private rooms: The fiscal advantage
}

I t may be necessary to arm-twist provincial regulators, while convincing hospital administrators that it's in their financial interest to provide more single patient rooms.

But the architects of a new Canadian standard for hospitals say the justification for private rooms in Canadian hospitals is so overwhelming that they expect the new guidelines will be "widely utilized."

"It's a prescription for reducing costs," while simultaneously moving to protect the safety of Canadians (www .cmaj.ca/lookup/doi/10.1503/cmaj.1094077), argues Bonnie Rose, president of the Canadian Standards Association (CSA), which recently introduced a private room requirement as part of the Health Care Facilities Standard Z8000, the first comprehensive national standard for the planning, design, and construction of Canadian health care facilities (http://shop.csa.ca/en/canada /landing-pages/z8000-canadian-health -care-facilities/page/z8000/).

The standard, developed with input from representatives of Health Canada and seven Canadian provinces, as well as experts in health care facility design and engineering, specifies that "all inpatient bedrooms in Class A HCFs shall be singled bedded."

Accreditation of Canadian hospitals is vested with the independent, nonprofit organization, Accreditation Canada, which requires that health care facilities be inspected on a three-year cycle to ensure that they are meeting a shared set of standards.

But it's unclear how the CSA's new facilities standard will fit with that and there's no suggestion that existing hospitals will have to refurbish facilities to provide more private rooms, although the CSA believes that would be of value.

"Within our standards we do expect organizations to comply with existing legislation and standards," says Wendy Nicklin, president and CEO of Accreditation Canada.

But she adds that the organization

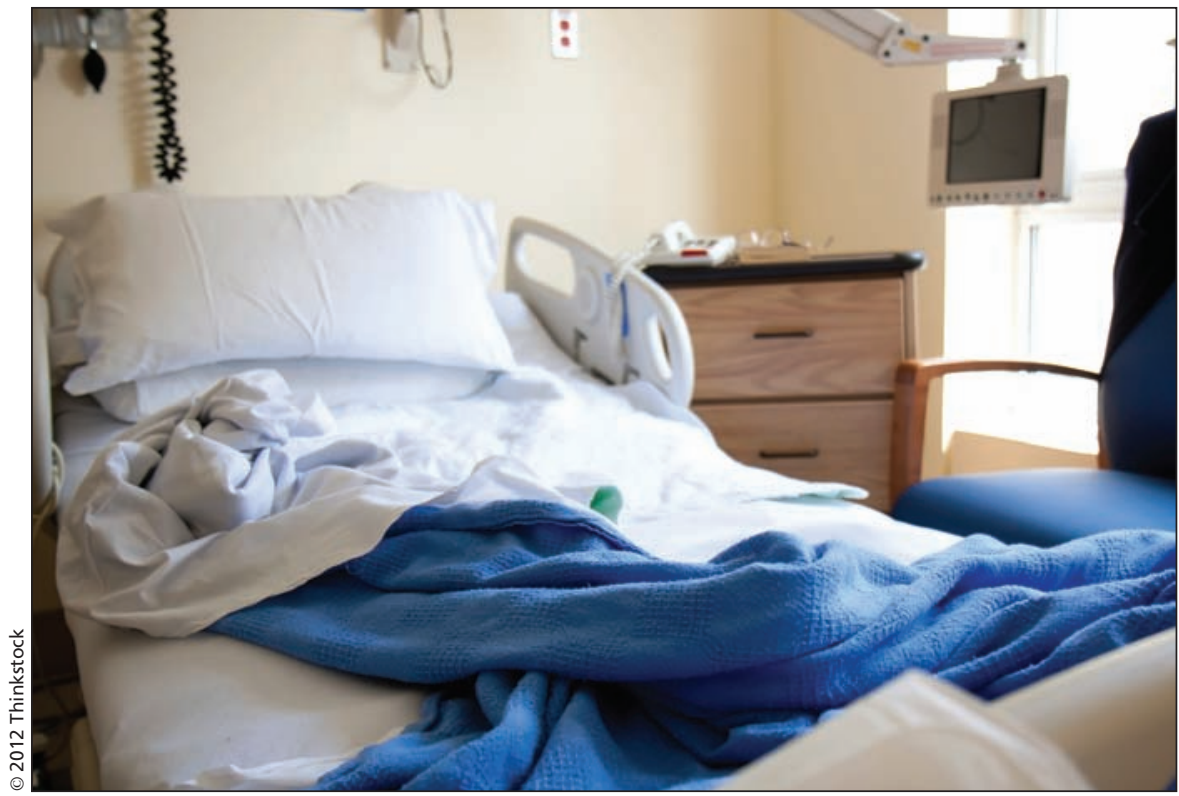

Many hospitals have a mix of single-bed and multi-bed rooms so that they can charge for the former, argues Tom Closson, president and CEO of the Ontario Hospital Association.

does not actually accredit facilities until construction has been completed and "for that kind of issue [private rooms] to not be on the table until an actual accreditation survey occurred to me would almost be too late to address the deficiency."

Nicklin hopes planners of new facilities would take the CSA standards into consideration. "From the standpoint of quality of care and infection rates ... that kind of direction is very, very important. I would hope that particular action or direction had been identified prior to [accreditation]."

CSA officials will be aggressively campaigning for adoption of the new standard. "That includes talking to those provincial organizations that do the contract work around ... public-private partnership facilities," as well as determining if "the standard [should] be part of any proposal made by contractors when they're building a new hospital. So we're exploring a number of ways to try and make sure that this standard is well utilized," says Doug Morton, the CSA's director of health and safety.
The standard also does not require existing health care facilities to renovate and convert multi-occupancy rooms to private rooms, Morton adds. "The issue is [that] most of the hospitals that currently exist in Canada are of an older variety. There's very few new hospitals. The view was that any element of the standard that an existing facility could implement, for example when it is doing refurbishment work, should be considered. But there certainly wasn't anything mandatory about it."

However, Tom Closson, president and CEO of the Ontario Hospital Association worries that there would be a huge loss of revenue for hospitals if they were built with $100 \%$ single-bedded rooms. Hospitals that have singlebed and multi-bed rooms can charge for the former, which generates substantial income, Closson explains.

"A big revenue source for hospitals is charging for private and semi-private accommodation. We don't know the total number that's brought in in Ontario for private and semi-private accommodation, but based on my experience ... we are probably talking about 
say $\$ 300$ to $\$ 400$-million dollars. As a conservative number, it would be at least \$200 million."

But Roger Ulrich, professor of architecture at Chalmers University in Gothenburg, Sweden and a global expert in health care design, says the debate over single-bed units "is a political or policy problem that's getting in the way of improving patient safety and should be examined and reconsidered."

It's "an artifact of the political system," Ulrich adds. "I don't know anyone in infection control who has a positive word to say about it. I think it should have been changed politically and it should all be $100 \%$."

The financial case for private rooms is so overwhelming that both those building new hospitals and those considering the refurbishment of existing ones should find the arguments compelling, Ulrich adds. "This area is just full of illusions unsupported or contradicted by data, like single rooms cost more. The traditional argument is untenable. It's kind of nonsense empirically."

Ulrich says that the operational costs of running a hospital for 30 years are at least 15 times higher than the initial capital costs. Building private rooms will increase your capital costs by $5 \%-10 \%$ but that will be recouped in three to five years "at the very most in a very conservative scenario," he argues.

That's supported by a recent cost comparison of private and semi-private hospital rooms conducted by Dr. Anthony Boardman, professor of business administration at the Sauder School of Business at the University of British Columbia in Vancouver (Journal of Benefit-Cost Analysis 2011; 2[1]:article 3). It found that private rooms were vastly superior on financial counts, as improved infection control, along with heightened privacy, improved sleep and fewer preventable medical errors contributed to reduced lengths of hospital stay. Taking everything into consideration, Boardman calculated the "net social benefit" (benefits minus costs) of a bed in private room compared to a semi-private room was about $\$ 70000$.

As compelling is research showing that single-occupancy rooms actually lead to higher hospital occupancy rates (Bobrow M, Thomas J. 2000: Building Type Basics for Healthcare Facilities. p. 145-57). Because of the need to isolate patients with nosocomial infections, hospitals with multi-bedded rooms can only reach a maximum occupancy of $80 \%-85 \%$.

Dr. Michael Gardam, director of infection prevention and control at the University Health Network in Toronto, Ontario, says a move toward $100 \%$ private rooms in Canadian hospitals will "be a relatively slower process unless the government stands up and takes leadership."

"There are places that have done this, that have had the vision and gone ahead and done it," such as The Hospital for Sick Children (SickKids) in Toronto, which was built in the 1980 s with $100 \%$ single rooms, he says.

Gardam adds that change will have to be driven by demand. "You're looking to the health care community and to patients standing up and saying that they want $100 \%$ single rooms." Nathan Stall, London, Ont.

CMAJ 2012. DOI:10.1503/cmaj.109-4078

Editor's note: Second of a three part series.

Part I: Private rooms: A choice between infection and profit (www.cmaj.ca/lookup/doi/10.1503 /cmaj.109-4077).

Next: Private rooms: Evidence-based design in hospitals. DOI: 10-1503 /cmaj.109-4079. 